\title{
Sanitation Practice of Slum Communities in Addis Ababa, Ethiopia
}

\author{
Abdissa Aga ${ }^{1}$, Walelegn Worku ${ }^{2}$ \\ ${ }^{1}$ School of Public Health, College of Health Sciences, University of Gondar, Gondar, Ethiopia \\ ${ }^{2}$ Addis Continental Institute of Public Health (ACIPH), Addis Ababa, Ethiopia
}

Email address:

abdi1459@gmail.com (A. Aga), abdissaga@gmail.com (A. Aga)

\section{To cite this article:}

Abdissa Aga, Walelegn Worku. Sanitation Practice of Slum Communities in Addis Ababa, Ethiopia. Science Journal of Public Health. Vol. 4, No. 4, 2016, pp. 297-304. doi: 10.11648/j.sjph.20160404.15

Received: May 16, 2016; Accepted: June 6, 2016; Published: June 23, 2016

\begin{abstract}
Globally, an estimated 2.5 billion people lack access to improved sanitation which is more than $35 \%$ of the world's population and about 1billion people, $15 \%$ of the world population do not have access to any kind of sanitation facility and exercise open defecation. A total of $16 \%$ of population living in urban Ethiopia do not have access to any kind of sanitation facility and exercise open defecation, of which the huge proportion lives in the slum areas. Objectives: To assess the level of practice and associated factors towards sanitation in the urban slum communities of Addis Ababa, Ethiopia. Methods: A community based cross-sectional study design was conducted on January 2015 in Addis Ketema, Lideta, Kirkos, and Gulelle sub cities of Addis Ababa. Using stratified sampling 636 sample households was selected and data was collected from 624 household, which is $98.1 \%$ of estimated sample size. Results: Practice of sanitation was $43.89 \%$ and it gets higher in households found in Lideta [AOR=3.37, 95\% $\mathrm{CI}=1.12-10.15, \mathrm{p}<0.031$ ], Kirkos [AOR=4.97, 95\% CI=1.76-14.04, $<<0.002$ ], and Gullele $[\mathrm{AOR}=10.16,95 \% \mathrm{CI}=3.61-28.58, \mathrm{p}<0.000]$ sub cities; and who own previous latrines $[\mathrm{AOR}=6.26,95 \%$ $\mathrm{CI}=3.01-13.01, \mathrm{p}<0.000]$. It gets lower in households who share latrine with other neighboring households $[\mathrm{AOR}=0.08,95 \%$ $\mathrm{CI}=0.03-0.17, \mathrm{p}<0.000]$, those who own simple pit latrines $[\mathrm{AOR}=0.02,95 \% \mathrm{CI}=0.05-0.74, \mathrm{p}<0.016]$, those who didn't receive support during the construction of their latrine, $[\mathrm{AOR}=0.004,95 \% \mathrm{CI}=0.001-0.014, \mathrm{p}<0.000]$, and those whose annual income is between 55,001 ETB and $65,000 \mathrm{ETB}[\mathrm{AOR}=0.15,95 \% \mathrm{CI}=0.02-0.88, \mathrm{p}<0.036]$. The level of practice of sanitation in the study population is low. Latrine sharing habit, not hiring sanitation facility builder/ skilled mason, and need for subsidy and support during latrine construction were found to be the main factors contributing for this low practice. Establishing well organized and responsible body at each level of administration that will incept and execute awareness and promotion activities to improve the practice of sanitation should be done using different promotion approaches.
\end{abstract}

Keywords: Sanitation, Practice, Urban Slums, Cross-Sectional Studies, Associated Factors, Ethiopia

\section{Introduction}

Sanitation is the application of different techniques and methods for the safe and sustainable management of human excreta, including the collection, storage, treatment, and disposal of feces and urine [1]. Globally, an estimated 2.5 billion people lack access to improved sanitation which is more than $35 \%$ of the world's population and about 1billion people, $15 \%$ of the world population do not have access to any kind of sanitation facility and exercise open defecation. This low coverage coupled with unsafe water causes around 1.6 million deaths of children with age less than five years [2].
Increasing the number of people with access to safe water supply, sanitation and hygiene has proven to be most effective but challenging throughout the developing world. Improving water, sanitation and hygiene has the potential to prevent at least $9.1 \%$ of the global disease burden and $6.3 \%$ of all deaths [3].

Access to safe sanitation services in Ethiopia is among the lowest in Sub-Saharan Africa with 56\% nationally, and $84 \%$ in the urban. Overall, $38 \%$ of households have no toilet facility, $16 \%$ in urban areas and $45 \%$ in rural areas [4]. Poor practice of sanitation by the community together with issues like poor financing towards sanitation infrastructures, low promotion activities, and gaps in monitoring and evaluation 
by the government are still the major causes for this low coverage and suffering of urban households, especially in slum areas.

Although sanitation has been a problem in different developing countries including Ethiopia, there is still a gap in measuring its practice at community level; and also identification of factors that affect sanitation practice and strategies to control them is yet to be established. Some studies in India and other developing countries have been conducted but they mainly focus on hygiene than sanitation [5 - 7].

This study focused on practice of sanitation in urban slum areas because the coverage of improved sanitation is very low and current way of sanitation improvement system should be changed. In addition, there is no other research conducted in the Ethiopian urban context to assess the sanitation practice of the community and set recommendations to solve the factors that hinder it. Thus, this study would be helpful for policy and decision makers in planning and implementation of sanitation strategies. It can also serve as a baseline research for sanitation programs and strategies that could be adopted or scaled-up in the near or far future by providing information on current community sanitation practices, opportunities, and challenges.

\section{Objectives}

\subsection{General Objective}

To assess the level of practice and associated factors towards sanitation among the slum communities of Addis Ababa.

\subsection{Specific Objectives}

- To describe the practice of sanitation by urban slum communities living in Addis Ababa.

- To identify factors associated with practice regarding sanitation in urban slum communities of Addis Ababa.

\section{Methods}

Study Area: The study was conducted in Addis Ketema, Lideta, Kirkos, and Gullele sub cities of Addis Ababa from October 2014 up to March 2015. The total study area encompasses about 64.48 square kilometers with total population over 1.2 million residents in 41 woredas of Addis Ababa.

Study Design: Community based cross-sectional study design was employed. Household owners in the study area,
Addis Ketema, Lideta, Kirkos, and Gullele sub cities, were considered to be the specific study units for this research. All households in the study area were eligible to be included in the study with the exclusion of public and private organizations or institutions; and commercial organizations.

Sample Size: The sample size was calculated by using the formula for estimation of single proportion for specific objective one due to the nature of the study design;

$$
\mathrm{n}=\mathrm{Z}_{\alpha / 2}^{2} * \mathrm{P}(1-\mathrm{P}) / \mathrm{d}^{2}
$$

Where $\mathrm{Z}$ value is 1.95 at $95 \% \mathrm{CI}$; $\mathrm{P}$ is the prevalence; and $\mathrm{d}$ is the margin error of estimation, which provides a sample of 384; and 423 households after taking an estimate of $10 \%$ non respondent rate.

For specific objective two, associated factors, sample size was computed by using the formula for two population proportions,

$$
\mathrm{n}=\left(\mathrm{Z}_{\alpha / 2}+\mathrm{Z}_{\beta}\right)^{2} *\left(\mathrm{p}_{1}\left(1-\mathrm{p}_{1}\right)+\mathrm{p}_{2}\left(1-\mathrm{p}_{2}\right)\right) /\left(\mathrm{p}_{1}-\mathrm{p}_{2}\right)^{2}
$$

And since there is no study done on this regard, the author was obligated to take the standard estimation of prevalence $50 \%$ and odds ratio of 2 to acquire the maximum sample size possible, which gives 296 samples and 326 after considering $10 \%$ non respondent rate.

The study used the maximum calculated sample size to address all its objectives, which is 423 . But considering minor demographic difference in the study areas and to correct errors that could happen due to a stratified sampling technique the study used a design effect of 1.5 and the acquired final sample size was 636 .

Sampling Procedures: The study used a stratified sampling technique to identify and acquire the required sample size, 636households, to address all its objectives; which was proportionally allocated for the four sub cities, that is 159 households per sub city. Because of the population difference between the sub cities ranges from $0.6 \%$ to $11.7 \%$ at most, the author believes the proportional allocation of study subjects will not cause any bias.

Then, after creating a stratum of high, middle, and low income woredas of each sub city based on their socioeconomic indicators, one sample woreda from each stratum of each sub city was selected by using a lottery method providing a total of 12 woredas with a sample of 53 households each. Finally the study participants were selected by using simple random sampling technique from a sampling registry obtained from the selected woreda health offices, i.e., Urban Health Extension Professionals' registry book/list.

Table 1. Stratum of woredas in Addis Ketema, Lideta, Kirkos, and Gullele sub cities based on their level of economy December 2014 [Data adopted from each

\begin{tabular}{|c|c|c|c|c|c|c|}
\hline \multirow{2}{*}{ Sub City } & \multicolumn{2}{|l|}{ Low income } & \multicolumn{2}{|l|}{ Middle income } & \multicolumn{2}{|l|}{ High income } \\
\hline & Woredas / Districts & Selected & Woredas / Districts & Selected & Woredas / Districts & Selected \\
\hline Addis Ketema & $7,8,9$ & 9 & $1,2,6,10$ & 2 & $3,4,5$ & 3 \\
\hline Lideta & $2,4,6,7$ & 7 & $1,3,9$ & 1 & $5,8,10$ & 5 \\
\hline Kirkos & $6,7,10$ & 10 & $1,2,8,11$ & 8 & $2,3,5,9$ & 5 \\
\hline Gullele & $1,5,6,7$ & 7 & $2,3,4$ & 4 & $8,9,10$ & 9 \\
\hline Total & 14 Woredas & 4 Woredas & 14 Woredas & 4 Woredas & 13 Woredas & 4 Woredas \\
\hline
\end{tabular}
sub city administration]. 
Procedure for Data Collection: Questionnaires used by WSP, UNICEF, and WHO in different developing countries for sanitation projects/scale-up programs were adopted, reviewed, and modified by the author and the advisor to include different indicators that will help address the study objectives in the urban slum context. The questionnaires were re-tested after the provision of one day training for both data collectors and supervisors (with experience of participating in data collection before; with no sex exception) before they were finally put to use.

Study Variables

Dependant / Outcome / Variables: Practice of sanitation

Independent / Explanatory / Variables:

- Socio-demographic variables (Age, Sex, Level of education, Income)

- Type of sanitation Product available

- Price of available sanitation products

- Place where sanitation products are available

- Promotion of sanitation products

Operational Definitions

Improved Sanitation: is sanitation facility that hygienically separates human excreta from human contact [2].

Unimproved Sanitation: is sanitation facility that does not ensure hygienic separation of human excreta from human contact [2].

Shared Sanitation Facilities: Sanitation facilities of an otherwise acceptable type shared between two or more households [2].

Adequate Practice: when the response of study participants is above the median of all the Practice questions.

Inadequate Practice: when the response of study participants is below or equal to the median of all the Practice questions.

\section{Data Quality Control}

All the collected questionnaires were properly organized and categorized according to their sub cities. They were reviewed, and ambiguous recordings due to hand writing or else were edited and cleared by the author and data collectors before entry. Care was taken not to discard any questionnaire that are incomplete or of non-respondent. After organizing and coding the entire necessary template the data entry was made by the author and trained data encoder (a trained professional with experience of data entry and template development for different research work) by using Epi info Version 3.5.4. The encoded data was exported to SPSS Version 20 for further analysis.

\section{Ethical consideration}

The ethical clearance was obtained from the institutional review board of University of Gondar before data collection is started. All study participants were adequately informed about the purpose, method and anticipated benefit of the study by the data collectors before collecting any data that was used for this study. They were clearly informed about options regarding voluntary participation in the study, and verbal consent was obtained from each participant willing to be part of the study. Also confidentiality of the study subjects was maintained and each and every data collected was only used for the sole purpose of this study.

\section{Results}

\subsection{Socio-demographic Status}

From a total sample of 636 randomly selected households $624(98.11 \%)$ respondents participated in the household survey, of which $421(67.5 \%)$ are female. About 39.6\% of respondents can't read and write followed by those who can only read and write (21\%), and a collective of $31.2 \%$ of participants have attended primary and secondary education, but those who have tertiary level education (over high school) is only $8.2 \%$. Regarding the main source of income, $47.4 \%$ of households depend on salary from their employment in governmental and private organizations, and $29 \%$ depend on their business trading, while the rest $23.6 \%$ of the households depend on other sources of income and monetary gifts from others. Over half of the study participants, $56.1 \%$, fail to disclose their total income during the past year whereas $27.1 \%$ and $7.4 \%$ of respondents claimed that they have earned less than 25,000 ETB and over 65,000 ETB respectively.

Table 2. Socio-demographic indicators of study participants in Addis Ketema, Lideta, Kirkos, and Gullele Sub Cities of Addis Ababa; January 2015 .

\begin{tabular}{lll}
\hline Variables $(\mathbf{n}=\mathbf{6 2 4})$ & Frequency & Percent \\
\hline Sex & 203 & 32.5 \\
Male & 421 & 67.5 \\
Female & & \\
Education & 247 & 39.6 \\
Can't read and write & 131 & 21.0 \\
Can read and write & 95 & 15.2 \\
Primary & 100 & 16.0 \\
Secondary & 51 & 8.2 \\
Tertiary & & \\
Occupation & 254 & 40.7 \\
Private Employee & 65 & 10.4 \\
Day Laborer & 112 & 17.9 \\
Civil Servant/ Gov't Employee & 193 & 30.9 \\
Other & & \\
Source of income & 296 & 47.4 \\
Salary & 181 & 29.0 \\
Business/Trading & 76 & 12.2 \\
Gift from others & 71 & 11.4 \\
Other & & \\
\hline
\end{tabular}

\subsection{Latrine Status}

A total of $93.1 \%$ of study households have latrine, of which, six out of ten $(65.4 \%)$, have unimproved pit latrine. The number of households that own improved hygiene and sanitation facility is only $26.2 \%$ (7.1\% flush/pour flush latrine and $19.1 \%$ VIP pit latrine); and 43 (6.9\%) of surveyed households does not own any kind of latrine. Of the surveyed households about $45.43 \%$ of latrines are shared ones.

About six out of every ten latrines have a lined pit septic tank and $29.1 \%$ have an unlined septic tank pit. Without 
considering minor material modifications and taking in to account of the use of local inputs, $70.7 \%$ and $21.7 \%$ of the observed latrines have concrete/ cement and wood/ mud latrine floors respectively. During the survey, the walls of the existing latrines was found out to be 55.2 brick/ concrete, $22.2 \% \mathrm{mud} /$ wood, $18.9 \%$ iron sheet. Regarding to the roofs of available sanitation facility, majority of them, $91.6 \%$, have iron sheet, while $2.9 \%$ have roof made of local salvage materials.

\subsection{Sanitation Practice}

\section{Defecation site}

Adult defecation site in the study participant household is dominated by shared latrine which is $61.50 \%$ followed by private latrine $31.40 \%$. This is also true for children; $25.50 \%$ communal latrine and $10.9 \%$ private latrine. The results for babies' fecal matter disposal shows that, out of the households who have babies, $70.49 \%$ households put it in to latrines, $23.50 \%$ dispose it in to garbage or ditch while the other $6.01 \%$ of the households leave it in the open.

\section{Latrine Functionality}

Out of the 581 latrines observed in the survey, 7 VIP pit latrines, 6 simple pit latrines, and 1 flush latrine, a total of 14 $(2.4 \%)$ latrines were found out to be non functional. The main reason for this non functionality of latrines was observed to be due to dirty and smelly latrines because of full pit/ septic tank of the latrines $(57.14 \%)$, broken slab (50\%), and missing superstructure (28.57\%).

\section{Improvements from Previous Latrine}

A total of $186(32.01 \%)$ households claimed to have a previous latrine before the one that they are currently using. These households have made some improvements on their current latrines compared to the one they used to own before. Thus, $43.31 \%$ has lined the pit with tight masonry coarse, $55.37 \%$ has improved wall, $53.76 \%$ has improved roof, and $54.83 \%$ has improved slab.

\section{Latrine Construction}

Though $24.8 \%$ of participants have other undisclosed reasons to build their latrine, $21.6 \%$ and $21.5 \%$ of the study participant households has constructed their latrine due to the construction of new house and subsidy offering from a program respectively. A total of 194 (31.1\%) households have received support during the construction of latrine of which $96.39 \%$ and $73.71 \%$ has received material and labor support from an organization, their relatives and/or neighbors respectively. About 101 (17.83\%) households have hired a mason/other professional to build their latrine with cost, $48.51 \%$, being the main criteria of selection.
Since practice of sanitation is mainly dependent on the availability of sanitation and/or latrine components at household level, it is only computed for latrine owners. And based on that, computing all the necessary variables and taking the median as a cutoff point to determine practice, about $43.9 \%$ of the surveyed households are practicing sanitation.

\subsection{Factors Affecting Practice of Sanitation in Slum Communities in Addis Ababa}

Sub City: compared to residents in Addis Ketema sub city, those living in Lideta $[\mathrm{AOR}=3.37,95 \% \mathrm{CI}=1.12-10.15$, $\mathrm{p}<0.031], \quad$ Kirkos $[\mathrm{AOR}=4.97, \quad 95 \% \quad \mathrm{CI}=1.76-14.04$, $\mathrm{p}<0.002]$, and Gullele $[\mathrm{AOR}=10.16,95 \% \mathrm{CI}=3.61-28.58$, $\mathrm{p}<0.000$ ] sub city have a better level of practice of sanitation.

Sharing Available Latrine: the practice of sanitation gets lower in households who share latrine with other neighboring households, $[\mathrm{AOR}=0.08,95 \% \mathrm{CI}=0.03-0.17, \mathrm{p}<0.000]$.

Type of Latrine: type of latrine owned by households was found to have a highly statistically significant association with the practice level of sanitation. Compared to those who own pour flush latrines, those who own simple pit latrines $[\mathrm{AOR}=0.02,95 \% \mathrm{CI}=0.05-0.74, \mathrm{p}<0.016]$, and other type of latrines $[\mathrm{AOR}=0.002,95 \% \mathrm{CI}=0.00-0.05, \mathrm{p}<0.000]$ were found to have lower level of practice.

History of owning previous latrine: households who have a history of owning a number of latrines through a period of time have found to practice sanitation more than those who own their first latrine, $[\mathrm{AOR}=6.26,95 \% \mathrm{CI}=3.01-13.01$, $\mathrm{p}<0.000]$.

Support during construction: the level of practice is low in households that didn't receive support during the construction of their latrine, $[\mathrm{AOR}=0.004,95 \% \mathrm{CI}=0.001-$ $0.014, \mathrm{p}<0.000]$ in the multivariate analysis.

Future Plans: households who don't plan to improve their latrine status in the future tend to have less level of practice than those who do have, $[\mathrm{AOR}=0.32,95 \% \mathrm{CI}=0.15-0.70$, $\mathrm{p}<0.000]$.

Hire Latrine Builder: compared to those households who hired skilled mason or latrine builder to construct their latrine, households who did not hire skilled mason have low level of practice of sanitation with $[\mathrm{AOR}=0.03,95 \% \mathrm{CI}=$ $0.008-0.13, \mathrm{p}<0.000]$.

Income: compared to those whose annual income is 25,000 ETB and less, those who earn 55,001 ETB - 65,000 ETB have low level of practice; $[\mathrm{AOR}=0.15,95 \% \mathrm{CI}=0.02$ $0.88, \mathrm{p}<0.036]$.

Table 3. Multivariate Analysis for Factors Affecting Practice of Sanitation in Slum Communities of Addis Ababa, Ethiopia; January 2015.

\begin{tabular}{|c|c|c|c|c|c|}
\hline \multirow{2}{*}{ Variables } & \multicolumn{2}{|c|}{ Practice } & \multirow{2}{*}{ Crude OR at $95 \%$ CI } & \multirow{2}{*}{ Adjusted OR at $95 \%$ CI } & \multirow{2}{*}{ p Value } \\
\hline & Yes & No & & & \\
\hline \multicolumn{6}{|l|}{ Sub city } \\
\hline Addis Ketema & 32 & 120 & 1 & 1 & \\
\hline Lideta & 43 & 103 & 1.56 & $3.37(1.12,10.15)^{*}$ & 0.031 \\
\hline Kirkos & 75 & 66 & 4.26 & $4.97(1.76,14.04)^{*}$ & 0.002 \\
\hline Gullele & 105 & 37 & 10.64 & $10.16(3.61,28.58)^{* *}$ & 0.000 \\
\hline Subsidy on sanitation is important & & & & & \\
\hline
\end{tabular}




\begin{tabular}{|c|c|c|c|c|c|}
\hline \multirow{2}{*}{ Variables } & \multicolumn{2}{|c|}{ Practice } & \multirow{2}{*}{ Crude OR at $95 \%$ CI } & \multirow{2}{*}{ Adjusted OR at $95 \%$ CI } & \multirow{2}{*}{ p Value } \\
\hline & Yes & No & & & \\
\hline Yes & 190 & 210 & 1 & 1 & \\
\hline No & 65 & 116 & 0.61 & $0.69(0.34,1.37)$ & 0.294 \\
\hline \multicolumn{6}{|l|}{ Sharing of available latrine with neighbors } \\
\hline Yes & 142 & 122 & 1 & 1 & \\
\hline No & 113 & 204 & 0.47 & $0.08(0.03,0.17)^{* *}$ & 0.000 \\
\hline \multicolumn{6}{|l|}{ Type of latrine owned by the household } \\
\hline Flush/Pour flush latrine & 23 & 21 & 1 & 1 & \\
\hline VIP latrine & 85 & 34 & 2.28 & $0.40(0.08,1.83)$ & 0.240 \\
\hline Pit latrine & 145 & 263 & 0.50 & $0.20(0.05,0.74)^{*}$ & 0.016 \\
\hline Other & 2 & 8 & 0.22 & $0.002(0.00,0.049)^{* *}$ & 0.000 \\
\hline \multicolumn{6}{|c|}{ The owned latrine is first latrine for household } \\
\hline Yes & 150 & 277 & 1 & 1 & \\
\hline No & 105 & 49 & 3.95 & $6.26(3.01,13.01)^{* *}$ & 0.000 \\
\hline \multicolumn{6}{|l|}{ Received support during latrine construction } \\
\hline Yes & 166 & 28 & 1 & 1 & \\
\hline No & 73 & 245 & 0.05 & $0.004(0.001,0.14)^{* *}$ & 0.000 \\
\hline Don't know & 16 & 53 & 0.05 & $0.009(0.002,0.03)^{* *}$ & 0.000 \\
\hline \multicolumn{6}{|l|}{ Future improvement plan } \\
\hline Yes & 87 & 102 & 1 & 1 & \\
\hline No & 168 & 224 & 0.86 & $0.32(0.15,0.70)^{*}$ & 0.004 \\
\hline \multicolumn{6}{|l|}{ Hired someone to build latrine } \\
\hline Yes & 84 & 17 & 1 & 1 & \\
\hline No & 171 & 309 & 0.11 & $0.03(0.008,0.136)^{* *}$ & 0.000 \\
\hline \multicolumn{6}{|l|}{ Reason to build first latrine } \\
\hline Program was offering subsidy & 91 & 43 & 1 & 1 & \\
\hline Someone told me I had to & 10 & 17 & 0.27 & $2.54(0.42,15.22)$ & 0.307 \\
\hline Had enough money to afford one & 5 & 21 & 0.11 & $0.27(0.04,1.63)$ & 0.154 \\
\hline Sick/Elder family member & 10 & 24 & 0.19 & $0.98(0.15,6.48)$ & 0.988 \\
\hline Construction of new house & 51 & 84 & 0.28 & $1.26(0.37,4.31)$ & 0.705 \\
\hline Neighbors had one & 10 & 14 & 0.33 & $3.63(0.71,18.49)$ & 0.120 \\
\hline Social phenomena & 6 & 6 & 0.47 & $1.48(0.08,27.04)$ & 0.791 \\
\hline Don't know & 5 & 29 & 0.08 & $0.34(.074,1.60)$ & 0.175 \\
\hline Other & 67 & 88 & 0.36 & $1.19(0.41,3.41)$ & 0.744 \\
\hline \multicolumn{6}{|l|}{ Final decision maker to construct latrine } \\
\hline Husband & 67 & 107 & 1 & 1 & \\
\hline Wife & 31 & 27 & 1.83 & $1.03(0.32,3.26)$ & 0.955 \\
\hline Husband and wife & 72 & 60 & 1.91 & $0.82(0.34,1.97)$ & 0.661 \\
\hline Whole family & 37 & 62 & 0.95 & $0.52(0.17,1.63)$ & 0.269 \\
\hline Other & 48 & 70 & 1.09 & $0.57(0.22,1.49)$ & 0.259 \\
\hline \multicolumn{6}{|l|}{ Raw material buyer for latrine construction } \\
\hline Hired body & 33 & 2 & 1 & 1 & \\
\hline Household head & 188 & 314 & 0.03 & $1.29(0.10,16.63)$ & 0.843 \\
\hline Household head and hired body together & 34 & 10 & 0.20 & $0.55(0.05,5.87)$ & 0.627 \\
\hline \multicolumn{6}{|l|}{ Income Group } \\
\hline $25,000 \mathrm{ETB}$ and less & 68 & 64 & 1 & 1 & \\
\hline 25,001 ЕТВ - 35,000 ЕТВ & 5 & 7 & 0.67 & $0.40(.021,7.60)$ & 0.544 \\
\hline 35,001 ЕТВ - 45,000 ЕТВ & 4 & 8 & 0.47 & $1.09(0.13,8.79)$ & 0.935 \\
\hline 45,001 ЕТВ - 55,000 ЕТВ & 7 & 2 & 3.29 & $8.41(0.75,94.44)$ & 0.084 \\
\hline 55,001 ЕТВ - 65,000 ЕТВ & 7 & 13 & 0.507 & $0.15(0.02,0.88)^{*}$ & 0.036 \\
\hline Over 65,000 ETB & 28 & 18 & 1.46 & $1.08(0.20,5.89)$ & 0.924 \\
\hline Not Disclosed & 136 & 214 & 0.59 & $0.98(0.42,2.27)$ & 0.968 \\
\hline
\end{tabular}

$* \mathrm{p}<0.05 * * \mathrm{p}<0.001$

\section{Discussion}

From the study findings, it can be said that the level of practice of sanitation in the community is not very high and as of the expected level. This can be explained from many different angles starting from type of available products, promotion channels used for awareness creation, socioeconomic and other determinant factors of the community, and policy issues.

Even though, based on the study finding, $93.1 \%$ of the households have access to sanitation facility, about $65.4 \%$ were unimproved pit latrines, and they were dominant in households with low economic income. The latrine preference shows that nearly all households prefer flush latrines for their households, but considering the expensiveness of this type of latrine, it is impossible to take these slum households to the top of the sanitation scale over night, or even in a short period of time. The next best desirable and economically acceptable preferred latrine was found out to be improved VIP latrines. Considering cost 
implications and easiness in operation and other aspects, targeting these slums to settle on this type of latrines is reasonable to the community. But still, creating demand on this type of products and influencing the community to make sanitation as one of the most important basic needs is the main pin point besides offering the community with many option of improved sanitation products. Similar results were found in other studies [8].

The study shows that, just over six out of ten households does not own their own latrine and share a latrine with other community members. This is found out to be one of the main factors contributing to the low practice of sanitation in the study population. This latrine sharing is also found in other developing countries including Bangladesh, Nepal, and Nigeria. According to a study conducted in these countries, households who don't have their own latrine, among poor families, just over half reported that they already had access to a toilet elsewhere [9].

Scaling up from current unimproved sanitation facility to the next close improved one is common in many countries and it was also observed in this study. For instance, households that have previous experience of owning unimproved latrine were now upgrading to a better and more likely to be called improved hygiene and sanitation facility by lining the pit, adding a quality slab, making the superstructure to a more privacy maintaining one, and the likes. The more improved sanitation facility they own from their previous one, households tend to have more future plan to upgrade their sanitation facility and highly engage in practicing sanitation.

Any financing for sanitation which does not flow directly from the immediately benefiting for the provision of sanitation goods and services can be defined as a subsidy [10]. The study findings show that those who received support during the construction of latrine were bound to have a good practice of sanitation and more likely to have improved sanitation status than others. These points towards the issue of subsidy and support of the urban poor related to hygiene and sanitation should not be ignored. This was also found to be true according to other studies $[11,12]$.

Though 7 out of 10 study participants are off to sanitation related subsidies in this study, it doesn't necessarily mean that each and every sanitation related activities should be subsidized for urban slums; rather segmenting those in critical need and addressing their issue should be taken as the best alternative. Because, the type of subsidy, according to this study, does not matter as long as it addresses the right fall backs of the community. Subsidy doesn't necessary mean money.

\section{Conclusion}

The level of practice of sanitation in the study population was found to be low. Low income households in these slum areas were most dominantly using unimproved pit latrines. Latrine sharing habit, hiring sanitation facility builder/ skilled mason, and need for subsidy and support during latrine construction was found out to be the main factors contributing for the low level of sanitation practice in the study population. The main reason for non functionality of household latrines was full pits, and the issue of delays and long waiting time to disluge/ empty the pits is found to be contributing to that.

\section{Recommendations}

Implementing the developed urban sanitation implementation strategic plan in a well organized and integrated manner by providing special attention to the poor segment of the community, especially in the slums is the first step.

Organizing and strengthening a responsible body that leads sanitation improvement activities at each level of administration, i.e., city, sub city, and woreda, should be done.

To improve the practice of sanitation, awareness creation and promotion activities should be incepted and executed.

Sanitation subsidy programs in slum areas should be designed and implemented in an integrated manner to improve the sanitation status of the slum community addressing the underlying causes of the problem.

Conducting other studies related to the sanitation service delivery system, effectiveness of hygiene and sanitation interventions could be helpful to understand the main issues related to factors beyond the community level and establish ways to overcome them.

\section{Acknowledgements}

I would like to acknowledge my advisor instructor Walelegn Worku for his prompt and constructive advises and supports that helped me develop a better and more solid research document. I would also like to thank University of Gondar and Addis Continental institute of Public Health for providing me the knowledge and opportunity to conduct this research in the best way possible.

The sub city health office and community development office experts' support in stratifying the woredas; and also active participation of urban health extension professionals of selected woredas in the identifying study units was very crucial and helpful. For that I would like to forward my heartfelt gratitude to them. Finally, I would like to thank Amref Health Africa for sponsoring the full expenses of this study, and all the study participants for being part of this research.

\section{References}

[1] UNICEF W. Joint Monitoring Programme (JMP) for Drinking Water Supply and Sanitation 2008 update. 2008.

[2] WHO U. Joint Monitoring Programme: Progress on Sanitation and Drinking Water 2013.

[3] Neil Buddy Shah SS, Andrew Fraker, Paul Wang, Esther Wang. Understanding Willingness to Pay for Sanitary Latrines in Rural Cambodia: Findings from Four Field Experiments of iDE Cambodia's Sanitation Marketing Program. October 2013. 
[4] Central Statistical Agency II. Ethiopia Demographic and Health Survey. March 2012.

[5] Richard Gelting,* Katherine Bliss, Molly Patrick, Gabriella Lockhart, and Thomas Handzel. Water, Sanitation and Hygiene in Haiti: Past, Present, and Future. The American Society of Tropical Medicine and Hygiene. 2013.

[6] USAID, UNC, Water SHED, LIEN AID, World Toilet Organization. WASH Marketing ProjectKampong Speu Baseline Survey, Final Report. February 2010

[7] Michael Roberts and Anthea Long. Demand Assessmentfor Sanitary Latrinesin Rural and Urban Areasof Cambodia. International Development Enterprises. March 2007.

[8] Michael Roberts, Aaron Tanner a, McNaughton A. Supply Chain Assessment for Sanitary Latrines in Rural and PeriUrban Areas of Cambodia. August 2007.

[9] WSP. Sustainability and equity aspects of total sanitation programmes. 2010.

[10] Christine Sijbesma CD, Catarina Fonseca, Christelle Pezon. IRC Symposium: Sanitation for the Urban Poor Partnership and Governance. Delft, The Netherlands: November 2008.

[11] Amaka Obika MJ, Valerie Curtis, Guy Howard T. Social Marketing For Urban Sanitation. October 2002.

[12] Sophie Trémolet PK, and Eddy Perez. Financing On-Site Sanitation for the Poor A Six Country Comparative Review and Analysis. January 2010.

[13] Andy Haines NB, Sandy Cairncross, Michael Davies, Katie Greenland AH, Steve Lindsay, Tom Lindsay DS, and Paul Wilkinson. Promoting Housing.pdf. 2012.

[14] Organization WH. UN-Water Global Annual Assessment of Sanitation and Drinking-Water (GLAAS). 2010.

[15] Program WaS, Bank TW. Water Supply and Sanitation in Sierra Leone: Turning Finance into Services for 2015 and Beyond

[16] Program WaS, Bank TW. Water Supply and Sanitation in Niger Turning Finance into Services for 2015 and Beyond.

[17] Program WaS, Bank TW. Water Supply and Sanitation in Mozambique: Turning Finance into Services for 2015 and Beyond.

[18] Program WaS, Bank TW. Water Supply and Sanitation in Central Africa Republic: Turning Finance into Services for 2015 and Beyond.

[19] Program WaS, Bank TW. Water Supply and Sanitation in Angola Turning Finance into Services for 2015 and Beyond.

[20] Bank TW. Sanitation and hygiene: why they matter. (http://web.worldbank.org/WBSITE/EXTERNAL/TOPICS/E XTWAT/EXTTOPSANHYG/0, contentMDK:21226306 menu PK:3747741 pagePK:64168445 piPK:64168309 theSitePK: 1923181 isCURL:Y,00.html).

[21] Padilla D. The Effectiveness Of Water, Hygiene, and Sanitation Interventions In Lowering Diarrheal Morbidity Across The Globe: A Systematic Review and Qualitative Analysis of Relevant Primary Literature. April 30, 2012.

[22] Annette Pr€uss-Ust€un JB, Thomas Clasen, John M. Colford Jr, Oliver Cumming, Valerie Curtis, Sophie Bonjour, Alan D.
Dangour, Jennifer De France, Lorna Fewtrell, Matthew C. Freeman, Bruce Gordon, Paul R. Hunter, Richard B. Johnston, Colin Mathers, Daniel M€ausezahl, Kate Medlicott, Maria Neira, Meredith Stocks, Jennyfer Wolf and Sandy Cairncross. Burden of disease from inadequate water, sanitation and hygiene in low- and middle-income settings: a retrospective analysis of data from 145 countries. August 2014.

[23] Sylvester J. Schieber C, Dana K. Bilyeu DRH, Marsha Rose Katz, Barbara B. Kennelly, Mark J. Warshawsky. The Unsustainable Cost of Health Care. September 2009.

[24] Morella SGBaE. Africa's Water and Sanitation Infrastructure Access, Affordability, and Alternatives. The International Bank for Reconstruction and Development The World Bank 2011.

[25] USAID WS, UNC. WASH Marketing Project Kampong Speu Baseline Survey. February 2010.

[26] Mr Guy Hutton P. Global costs and benefits of drinking-water supply and sanitation interventions to reach the MDG target and universal coverage. 2012.

[27] Company TN. Understanding Sanitation Habits A Qualitative Study in East Java Indonesia (Probolinggo \& Pacitan). March 26,2008 .

[28] Organization. WH. 10 facts on sanitation. 2012.

[29] AMCOW W, UNICEF, WaterAid and CREPA. Sanitation and Hygiene in Africa at a Glance A Synthesis Of Country Priority Actions. July 2011.

[30] Frias J. Opportunities to Improve Sanitation: Situation Assessment of Sanitation in Rural East Java, Indonesia. April 2008 .

[31] Pacific (WSP-EAP) WaSPEAat. Selling Sanitation in Vietnam. January 2002.

[32] Region WaSP-EAatPW-EWB-EAatP. Economic impacts of Sanitation in Southeast Asia. November 2007.

[33] Energy FDRoEMoWa. Urban Sanitation Universal Access Plan. December 2011.

[34] (ODI) WaSftUPWatODI. Progress Linked Finance: a study of the feasibility and practicality of a proposed WASH financing approach. November 2011.

[35] Program WaS, Bank TW. Water Supply and Sanitation in Ethiopia: Turning Finance into Services for 2015 and Beyond.

[36] Ashish Joshi SP, Jyoti B Kasav, Mehak Segan, and Awnish K Singh. Water and Sanitation Hygiene Knowledge Attitude Practice in Urban Slum Settings. September 29, 2013.

[37] (WSP-EAP) WaSPEAatP. Selling Sanitation in Vietnam What Works? January 2002.

[38] WSP JDaCK. Introductory Guide to Sanitation Marketing. September 2011.

[39] WSP U, Water Aid, CREPA. Sanitation and Hygiene in Africa at a Glance, A synthesis of country priority actions. 2011.

[40] Eduardo Perez with Jason Cardosi YC, Jacqueline Devine, Amy Grossman, Craig Kullmann, C. Ajith Kumar, Nilanjana Mukherjee, Manu Prakash, Amin Robiarto, Deviariandy Setiawan, Upneet Singh, and Djoko Wartono: WSP. What Does It Take to Scale Up Rural Sanitation? July 2012. 
[41] Al EPe. Progress Report: July 1, 2009-June 30, 2010; http://www-wds.worldbank.org. 2011.
[42] Habitat U. The challenge of slums: global report on human settlements 2003. Chapter 1: development context and the millennium agenda. revised and updated version. 2010. 